\title{
A pilot study assessing whether African American women visiting the emergency department give different answers than an anonymous, internet-based population
}

\author{
Mandy J. Hill ${ }^{*}$ and Richard M. Grimes \\ *Correspondence: Mandy.J.Roberts@uth.tmc.edu CrossMark
}

University of Texas Health Science Center at Houston, Medical School, 6431 Fannin, JJL 420, Houston Texas 77030, USA.

\begin{abstract}
Background: Preventive vaccine uptake by adults in the United States is poor. For all reported preventive vaccines, the national rate of immunizations is lower for African Americans than for Whites, Hispanics or Asians. There is also a racial disparity in uptake of the vaccine for pathogenic human papillomavirus (HPV) with African American women being less likely to complete the three shot series. This study sought to determine if different information would be obtained from a group of young African American women responding to an internet based survey versus when that instrument was completed in-person at a medical venue. The subject matter of the survey was the willingness to participate in a study using a smartphone application aimed at improving HPV vaccine uptake.

Methods: A survey was administered to 40 young African American women aged 18-26 years, 19 seeking non-emergent care in an emergency department (ED) and 21 recruited online via a social networking site and email.

Results: Analyses utilizing an independent t-test and chi-square test (respectively) confirmed differences in the ED versus the internet population with regard to education $(\mathrm{P}=0.000 \mathrm{P}=0.001)$, age at sexual debut $(\mathrm{P}=0.03 ; \mathrm{P}=0.03)$, and payment source for health care $(\mathrm{P}=0.03 ; 0.09)$. The entire internet group had some college education, but $42.1 \%$ of the ED respondents had less than a college education. The ED group was less likely (31.6\%) to rely on private insurance to pay for their care than the internet group (57.1\%). Marginally significant findings between the two groups were noted with consistent sexual partner $(\mathrm{P}=0.08 ; \mathrm{P}=0.11)$. Most study participants were comfortable with an HPV application on their smartphone and used them frequently in both populations.

Conclusion: Study findings suggest there is significant variance in the education level, age at sexual debut, and payment source for healthcare among study subjects recruited in different populations based on settings and survey medium. However, superiority of the data collected from these two mediums cannot be confirmed. Further research is needed comparing delivery approaches of selfreported survey methods based on setting and medium.
\end{abstract}

Keywords: Emergency department, survey methodology, internet based surveys, face-to-face surveys, human papillomavirus, smartphone

\section{Introduction}

African Americans visit the emergency department (ED) at twice the rate of Whites $[\mathbf{1}, \mathbf{2}]$. EDs also provide care to populations that are vulnerable to HIV and sexually transmitted infections (STI), including the human papillomavirus (HPV) [3]. Existing literature reveals extremely high STI rates in EDs [3-8]. The Center for Disease Control \& Prevention and the United States Preventive Services Task Force (USPSTF) recognize the ED as an important clinical setting for STI prevention [3,9]. CDC reports that African American women are far more likely to contract STIs [10]. Therefore, it is important to conduct surveys to assess readiness for STI prevention efforts in an ED setting among high risk persons, such as African American women. Such surveys will provide data confirming or negating the acceptability of STI prevention messages. In addition, survey tools and data obtained from an ED population can be compared to women recruited from different environments and who may demographically differ.
The internet has been frequently used to survey individuals with regard to health related matters $[11,12]$. These surveys have been particularly useful in obtaining responses from surveys on sensitive topics such as sexual behaviors and drug abuse [13-15]. The internet provides a way of accessing large numbers of individuals at a very low cost. Respondents can choose to: participate or not, remain anonymous, and give responses without fear of repercussions. However, it should be recognized that internet based surveys yield biased results which cannot be generalized. Aside from the fact that not everyone has a computer, tablet, or smartphone, there is clear evidence that these biases may be quite significant when the surveys deal with stigmatized behaviors. For example, men who have sex with men (MSM) who respond to internet surveys present a different risk profile than those who are recruited from Gay bars or other venues [16-18]. This may be the result of MSMs altering their risks depending on the venue that they use to meet sex partners [19]. There is also evidence that the design 
Hill et al. Emergency Medicine and Health Care 2014,

and administration of an internet based survey can also alter the responses. Rosser et al., found that MSM were less likely to participate in studies where the survey was long, if the respondents were not being paid, there was concern that there was a risk of breach of confidentiality, if the survey had a high degree of difficulty, individuals thought of themselves as being too busy, and/or questions had sexual content [20]. These studies have been conducted among MSM and certainly provide evidence of potential biases within that population. However, there is a paucity of studies that have examined the kinds of bias that might be introduced in internet based studies of sensitive topics in heterosexual, minority women.

Therefore, a study was designed to determine if minority, heterosexual women recruited from an ED would have a different demographic profile and would provide different responses to the same questions than respondents who were recruited from the internet. The study queried the two groups of young African-American women as to whether they would be willing to have a smartphone application (app) that would provide information about the HPV vaccine. Apps have often been used to provide information and reminders to individuals about health related topics $[\mathbf{2 1 , 2 2 ]}$. The HPV vaccine was chosen as a topic that is associated with sexual behavior and might be considered sensitive. It was expected that the internet population would have a higher income, be more likely to have health insurance, be more knowledgeable about HPV prevention, have lower risks for STIs, and be more likely to accept STI prevention messages.

\section{Methods}

\section{Recruitment}

Participants were recruited from two settings: a local hospital's ED and online via a social networking site or email. A thirty item survey was given over a four month period to a convenience sample of 40 African American women aged 18-26 years, who either completed an online survey $(n=21)$ or sought nonemergent care in a local ED of a Level I Trauma hospital $(n=19)$. Women recruited from the ED who (1) identified themselves as African-American, (2) owned a smartphone, and (3) had been cleared for discharge from the ED were approached and informed about the study by a research associate. Women recruited from the ED were informed about the details of the study and provided informed consent. Women recruited on the internet were able to respond anonymously to the survey.

The survey included measures from previously used surveys that assessed patient's knowledge [23,24], attitudes [24], beliefs [23], potential barriers to HPV vaccination [25], and acceptability of HPV vaccinations among young adults [26]. Questions used in these manuscripts were modified and tailored toward the demographic characteristics of the study population. Additional questions concerning comfort with a smartphone and acceptability were added by the researcher. The study was approved by the University of Texas Health Science Center at Houston's Committee for the Protection of
Human Subjects, the institutional review board.

\section{Measures \\ Dependent variables}

The categorical value 'perceived willingness to participate in a smartphone app based research project encouraging HPV vaccine uptake' is designated as the outcome variable for this study. The question read, 'If given the opportunity to participate in a research project where you would get a free, interactive application on your smartphone to evaluate your willingness to get the HPV vaccine (at no cost), would you participate? The response was a yes/no format.

\section{Independent variables}

Categorical variables included demographics: age, monthly income, education, sexual preference, contraception use, having a consistent sexual partner, history of a (STI), history of HIV/STI testing, number of lifetime sexual partners, age at sexual debut, usual source of care, and payment source for health care; HPV vaccine uptake questions: actual receipt of HPV vaccine; HPV knowledge based questions: knowledge of HPV prevention methods; and smartphone based questions: frequency of smartphone app use and comfort with an STI (HPV) app on smartphone.

\section{Statistical analysis}

Fisher's exact test and chi square analysis were used to determine the difference between the demographic and behavioral variables and smartphone usage. A t-test was used to analyze the relationships between the demographic and behavioral variables and the willingness to participate in a research study that used an app for the HPV vaccine.

\section{Results}

The majority of subjects recruited from both the ED and the internet were 21 years of age or older, had a monthly income of $\$ 1,000$ or more, were heterosexual, did not have a history of an STI, had a sexual debut between 16 and 17 years of age, reported a history of HIV/STI testing, reported 1 sexual partner, had a usual source of care, had not received the HPV vaccine, and had knowledge of condom use and HPV vaccine receipt as known HPV prevention methods. The internet population differed from the ED population with regard to education $(P=0.003)$, age at sexual debut $(P=0.05)$, and payment source for health care $(\mathrm{P}=0.03)$ (Table 1). Approximately two-thirds of both groups reported that they were frequent users of their smartphones. There were no significant differences between the two groups with regard to their comfort with having an HPV related app on their smartphone (Table 2). The data were also analyzed, stratified by ED or internet, to determine whether demographic or behavioral variables predicted whether the respondents would be willing to use the smartphone app. Predictors of willingness differed when comparing the internet population to the ED population on 
Hill et al. Emergency Medicine and Health Care 2014,

http://www.hoajonline.com/journals/pdf/2052-6229-2-2.pdf

doi: $10.7243 / 2052-6229-2-2$

Table1. Demographic analysis comparing internet population to ED population.

\begin{tabular}{|c|c|c|c|c|c|}
\hline Variable & Categories of Variable & Total $(\mathrm{N}=40)$ & $\mathrm{ED}(\mathrm{N}=19)$ & Internet $(\mathrm{N}=21)$ & $P$-value \\
\hline \multirow[t]{2}{*}{ Education } & No college & $8(20.0 \%)$ & $8(42.1 \%)$ & $0(0.0 \%)$ & 0.001 \\
\hline & Some college & $32(80.0 \%)$ & $11(57.9 \%)$ & $19(100 \%)$ & -- \\
\hline \multirow[t]{2}{*}{ Age at sexual debut ${ }^{\mathrm{a}}$} & $<18$ years & $21(53.8 \%)$ & $13(72.2 \%)$ & $8(38.1 \%)$ & 0.05 \\
\hline & $\geq 18$ years & $18(46.2 \%)$ & $5(27.8 \%)$ & $13(61.9 \%)$ & -- \\
\hline Payment Source & Private & $18(45.0 \%)$ & $6(31.6 \%)$ & $12(57.1 \%)$ & 0.03 \\
\hline \multirow[t]{2}{*}{ (Insurance) } & No & $10(25.0 \%)$ & $4(21.1 \%)$ & $6(28.6 \%)$ & -- \\
\hline & Government & $12(30.0 \%)$ & $9(47.4 \%)$ & $3(14.3 \%)$ & -- \\
\hline Consistent sexual & Yes & $26(65.0 \%)$ & $15(78.9 \%)$ & $11(52.4 \%)$ & 0.10 \\
\hline partner & No & $14(35.0 \%)$ & $4(21.1 \%)$ & $10(47.6 \%)$ & -- \\
\hline \multirow[t]{2}{*}{ Age } & $<21$ years & $10(25.0 \%)$ & $4(21.1 \%)$ & $6(28.6 \%)$ & 0.72 \\
\hline & $\geq 21$ years & $30(75.0 \%)$ & $15(78.9 \%)$ & $15(71.4 \%)$ & -- \\
\hline \multirow[t]{2}{*}{ Monthly Income } & $<\$ 1,000$ & $14(25.0 \%)$ & $6(31.6 \%)$ & $8(38.1 \%)$ & 0.74 \\
\hline & $\geq \$ 1,000$ & $26(65.0 \%)$ & $13(68.4 \%)$ & $13(61.9 \%)$ & -- \\
\hline \multirow[t]{2}{*}{ Sexual preference } & Women & $2(5.0 \%)$ & $0(0.0 \%)$ & $2(9.5 \%)$ & 0.48 \\
\hline & Men & $38(95.0 \%)$ & $19(100 \%)$ & $19(90.5 \%)$ & -- \\
\hline \multirow[t]{3}{*}{ Contraception use } & Male condom & $16(40.0 \%)$ & $9(47.4 \%)$ & $7(33.3 \%)$ & 0.59 \\
\hline & Other & $13(32.5 \%)$ & $6(31.6 \%)$ & $7(33.3 \%)$ & -- \\
\hline & None & $11(27.5 \%)$ & $4(21.1 \%)$ & $7(33.3 \%)$ & -- \\
\hline \multirow[t]{2}{*}{ History of a STI } & Yes & $7(17.5 \%)$ & $3(15.8 \%)$ & $4(19.0 \%)$ & 1.00 \\
\hline & No & $33(82.5 \%)$ & $16(84.2 \%)$ & $17(81.0 \%)$ & -- \\
\hline \multirow{2}{*}{$\begin{array}{l}\text { History of HIV/STI } \\
\text { testing }\end{array}$} & Yes & $27(67.5 \%)$ & $13(68.4 \%)$ & $14(66.7 \%)$ & 1.00 \\
\hline & No & $13(32.5 \%)$ & $6(31.6 \%)$ & $7(33.3 \%)$ & -- \\
\hline Number of sex & 0 & $8(20.0 \%)$ & $4(21.1 \%)$ & $4(19.0 \%)$ & 0.59 \\
\hline \multirow[t]{2}{*}{ partners } & 1 & $22(55.0 \%)$ & $9(47.4 \%)$ & $13(61.9 \%)$ & -- \\
\hline & 2 or more & $10(25.0 \%)$ & $6(31.6 \%)$ & $4(19.0 \%)$ & -- \\
\hline \multirow[t]{2}{*}{ Usual source of care } & Yes & $29(72.5 \%)$ & $14(73.7 \%)$ & $15(71.4 \%)$ & 1.00 \\
\hline & No & $11(27.5 \%)$ & $5(26.3 \%)$ & $6(28.6 \%)$ & -- \\
\hline Actual receipt of HPV & Yes & $7(17.5 \%)$ & $4(21.1 \%)$ & $3(14.3 \%)$ & 0.69 \\
\hline Vaccine & No & $33(82.5 \%)$ & $15(78.9 \%)$ & $18(85.7 \%)$ & -- \\
\hline Perceived availability & Less Likely & $10(25.0 \%)$ & $5(26.3 \%)$ & $5(23.8 \%)$ & 1.00 \\
\hline of the HPV vaccine & More Likely & $30(75.0 \%)$ & $14(73.7 \%)$ & $16(76.2 \%)$ & -- \\
\hline \multirow[t]{4}{*}{ Knowledge of HPV prevention methods ${ }^{\mathrm{b}}$} & Having 1 sex partner & $12(30.0 \%)$ & $3(7.5 \%)$ & $9(22.5 \%)$ & 0.60 \\
\hline & Avoid polygamous sex partner & $14(35.0 \%)$ & $6(15.0 \%)$ & $8(20.0 \%)$ & -- \\
\hline & Use a condom & $29(72.5 \%)$ & $13(32.5 \%)$ & $16(40.0 \%)$ & -- \\
\hline & HPV vaccination & $36(90.0 \%)$ & $17(42.5 \%)$ & $19(47.5 \%)$ & -- \\
\hline
\end{tabular}

$\mathrm{a}=$ one respondent did not answer this question. $\mathrm{b}=$ more than one answer was allowed.

the basis of education ( $p=0.001)$, age at sexual debut $(p=0.05)$, payment source for health care $(P=0.09)$, and the presence of a consistent sexual partner $(p=0.08)$ (Table 3$)$.

\section{Discussion}

This is the first study to assess if young adult, African American women, recruited online or in-person, would respond to the same survey in the same manner. It had been expected that the internet population would be more likely to have health insurance, be more knowledgeable about HPV prevention, have lower behavioral risks for STIs, and be more likely to accept STI prevention messages. Findings showed the only differences that conformed to the original expectations were that the internet group was more likely to have health insurance. While there were no difference in the willingness of the two groups to have a smartphone app with HPV information, it is 
Hill et al. Emergency Medicine and Health Care 2014,

http://www.hoajonline.com/journals/pdf/2052-6229-2-2.pdf

Table 2. Summary statistics of smartphone app related variables.

\begin{tabular}{|c|c|c|c|c|}
\hline Variable & Total $(\mathrm{N}=40)$ & $\mathrm{ED}(\mathrm{N}=19)$ & Internet $(\mathrm{N}=21)$ & $P$-value \\
\hline \multicolumn{5}{|c|}{ Frequency of mobilephone use } \\
\hline Infrequently & $12(30.0 \%)$ & $6(31.6 \%)$ & $6(28.6 \%)$ & $0.70^{\mathrm{a}}$ \\
\hline Frequently & $28(70.0 \%)$ & $13(68.4 \%)$ & $15(71.4 \%)$ & -- \\
\hline \multicolumn{5}{|c|}{ Comfort with an STI (HPV) mobile application on mobile phone } \\
\hline Not comfortable & $10(25.0 \%)$ & $4(21.1 \%)$ & $6(28.6 \%)$ & $0.40^{\mathrm{b}}$ \\
\hline $\begin{array}{l}\text { Partially } \\
\text { comfortable }\end{array}$ & $12(30.0 \%)$ & $5(26.3 \%)$ & $7(33.3 \%)$ & -- \\
\hline Comfortable & $18(45.0 \%)$ & $10(52.6 \%)$ & $8(38.1 \%)$ & -- \\
\hline
\end{tabular}

$a=$ Fishers exact test; $b=t$ test.

Table 3. Chi-square analysis of differences, stratified by setting, in the demographic and behavioral variables and the perceived willingness to participate in a smartphone application based research project.

\begin{tabular}{lll}
\hline Variable & $\boldsymbol{a}^{2}$ & $\boldsymbol{P}$-value \\
\hline Education & 11.05 & $0.001^{*}$ \\
Age at sexual debut & 4.54 & $0.05^{*}$ \\
Payment source & 5.31 & $0.09^{*}$ \\
Consistent sexual partner & 3.10 & 0.08 \\
Comfort with an STI (HPV) app on mobile phone & 0.30 & 0.58 \\
Contraception & 1.05 & 0.59 \\
History of HIV/STI testing & 0.01 & 0.91 \\
Number of sexual partners & 1.03 & 0.59 \\
Usual source of care & 0.03 & 0.87 \\
Actual receipt of HPV vaccine & 0.32 & 0.57 \\
Perceived availability of the HPV vaccine & 3.90 & 0.42 \\
Knowledge of HPV prevention methods & 2.36 & 0.31 \\
\hline
\end{tabular}

${ }^{\star}$ Fisher's Exact Test p-value.

important to note that one quarter of the respondents were not comfortable with having the app on their smartphone. The fact that there were no differences between the groups suggests that social and cultural norms persist and are not altered by demographic or venue differences. While the venue of recruitment was not important, the study does raise the question of whether the smartphone is a universal means of educating about sensitive topics in this population.

When interpreting these results, one should realize that there is conflicting literature and data regarding the validity of survey data obtained from the internet regarding sensitive topics among minority populations. While a research group found internal consistency and test-retest reliability coefficients when comparing Internet and telephone administered measures [27]; another study challenged the validity of responses received from an internet based survey, particularly among stigmatized persons [20]. An additional study showed test-retest reliability across Internet and telephone survey administration exceeded the minimal threshold of $70 \%$ for most of the measures, indicating strong agreement between the two survey methods [28]. Other published findings provide reassurance to future researchers exploring the internet as a study setting that useful information can be obtained from internet respondents [29].

These findings suggest the ED can be a place to provide STI prevention messages to African American women and that this population will provide behavioral information in that setting. ED researchers may consider experimenting with smartphone apps to educate patients. It has been shown that $52 \%$ of smartphone owners have used their phones to look up health or medical information, a finding with relevance to researchers exploring trends related to young people and African Americans, as these groups are more likely to have mobile internet access [30]. A smaller portion of Americans, $19 \%$ of smartphone owners, have downloaded an app to track or manage their health information [30].

\section{Limitations}

The primary limitation of the study is the small sample size. Clearly this pilot study needs to be replicated with a larger sample size in other settings, including the internet and the ED. The Likert scale assessing comfort with an HPV application on a smartphone did not have a neutral option, thus, this may have limited the investigator's ability to discern variances in comfort among individuals who were neutral in opinion. Another study limitation is that the data was based on self-report. The survey questions assessing comfort with and acceptability of smartphones for prevention apps have not been validated.

\section{Conclusions}

This published study enrolled racial/ethnic minorities of low socioeconomic status; thus, findings strengthen the notion that internet based research among this subgroup can be conducted [29]. Future research is needed to compare the reliability of data collected from the Internet and face-to-face survey. Researchers are advised to use equivalent questions to ensure consistency of items and scales in different venues [29]. Discerning differences aids in improving reliability, validity, and equivalence of measures across mediums, and assists in identifying sources of error or systematic measurement bias [29].

\section{Competing interests}

The authors declare that they have no competing interests.

Authors' contributions

\begin{tabular}{|l|c|c|}
\hline Authors' contributions & MJH & RMG \\
\hline Research concept and design & $\checkmark$ & -- \\
\hline Collection and/or assembly of data & $\checkmark$ & -- \\
\hline Data analysis and interpretation & $\checkmark$ & $\checkmark$ \\
\hline Writing the article & $\checkmark$ & $\checkmark$ \\
\hline Critical revision of the article & $\checkmark$ & $\checkmark$ \\
\hline Final approval of article & $\checkmark$ & $\checkmark$ \\
\hline Statistical analysis & $\checkmark$ & $\checkmark$ \\
\hline
\end{tabular}


Hill et al. Emergency Medicine and Health Care 2014,

http://www.hoajonline.com/journals/pdf/2052-6229-2-2.pdf

doi: $10.7243 / 2052-6229-2-2$

\section{Acknowledgement}

This publication was made possible with departmental funding from the University of Texas Health Science Center at Houston, Department of Emergency Medicine and the Baylor-UTHouston Center for AIDS Research (CFAR), an NIH funded program (Al036211).

Publication history

Editor: Peter E. Hilsenrath, University of the Pacific, USA. EIC: Joseph Varon, University of Texas Medical Branch, USA. Received: 15-May-2014 Final Revised: 17-Jun-2014

Accepted: 20-Jun-2014 Published: 26-Jun-2014

\section{References}

1. Pitts SR, Niska RW, Xu J and Burt CW. National Hospital Ambulatory Medical Care Survey: 2006 emergency department summary. Natl Health Stat Report. 2008; 1-38. I PubMed

2. Policy. Prevention. Leadership, S.C.P.H.I. A Report on Frequent Users of Hospital Emergency Departments in South Carolina. 201. I Website

3. Haukoos JS, Mehta SD, Harvey L, Calderon Y and Rothman RE. Research priorities for human immunodeficiency virus and sexually transmitted infections surveillance, screening, and intervention in emergency departments: consensus-based recommendations. Acad Emerg Med. 2009; 16:1096-102. | Article | PubMed

4. Monroe KW, Weiss HL, Jones M and Hook EW, 3rd. Acceptability of urine screening for Neisseria gonorrheae and Chlamydia trachomatis in adolescents at an urban emergency department. Sex Transm Dis. 2003; 30:850-3. | Article | PubMed

5. Bachmann LH, Pigott D, Desmond R, Jones M, Lumpkins J, Gala P, Terndrup T and Hook EW, 3rd. Prevalence and factors associated with gonorrhea and chlamydial infection in at-risk females presenting to an urban emergency department. Sex Transm Dis. 2003; 30:335-9. | Article I PubMed

6. Todd CS, Haase $\mathrm{C}$ and Stoner BP. Emergency department screening for asymptomatic sexually transmitted infections. Am J Public Health. 2001; 91:461-4. | PubMed Abstract | PubMed Full Text

7. Mehta SD, Rompalo A, Rothman RE, Londner MS and Zenilman JM. Generalizability of STD screening in urban emergency departments: comparison of results from inner city and urban sites in Baltimore, Maryland. Sex Transm Dis. 2003; 30:143-8. | Article | PubMed

8. Mehta SD, Rothman RE, Kelen GD, Quinn TC and Zenilman JM. Unsuspected gonorrhea and chlamydia in patients of an urban adult emergency department: a critical population for STD control intervention. Sex Transm Dis. 2001; 28:33-9. | Article | PubMed

9. Meyers D, Wolff T, Gregory K, Marion L, Moyer V, Nelson H, Petitti D and Sawaya GF. USPSTF recommendations for STI screening. Am Fam Physician. 2008; 77:819-24. | Article | PubMed

10. Center for Disease Control and Prevention, C. 2010 Sexually Transmitted Diseases Surveillance. 2011. | Article

11. Rhodes SD, Bowie DA and Hergenrather KC. Collecting behavioural data using the world wide web: considerations for researchers. J Epidemiol Community Health. 2003; 57:68-73. | Article | PubMed Abstract | PubMed Full Text

12. Johansen MA, Henriksen E, Berntsen $G$ and Horsch A. Electronic symptom reporting by patients: a literature review. Stud Health Technol Inform. 2011; 169:13-7. | Article | PubMed

13. Daneback $K$ and Ross MW. The complexity of internet sexuality. Adv Psychosom Med. 2011; 31:121-34. | Article | PubMed

14. Taylor $M$ and Joshi A. Surveys assessing STI related health information needs of adolescent population. Technol Health Care. 2012; 20:247-61. I Article | PubMed

15. Miller P.G. and A.L Sonderlund. Using the internet to research hidden populations of illicit drug users: a review. Addiction. 2010; 105:1557-67. | Article

16. He Q, Peng WJ, Zhang JQ, Wang BX and Wang J. Prevalence of unprotected anal intercourse and unprotected vaginal intercourse among HIV-positive men who have sex with men in China: a metaanalysis. Sex Transm Infect. 2012; 88:229-33. | Article | PubMed

17. Mustanski BS, Newcomb ME, Du Bois SN, Garcia SC and Grov C. HIV in young men who have sex with men: a review of epidemiology, risk and protective factors, and interventions. J Sex Res. 2011; 48:218-53. | Article | PubMed Abstract | PubMed Full Text

18. Sullivan PS, Grey JA and Simon Rosser BR. Emerging technologies for HIV prevention for MSM: what we have learned, and ways forward. J Acquir Immune Defic Syndr. 2013; 63 Suppl 1:S102-7. | Article I PubMed Abstract | PubMed Full Text

19. O'Leary A, Horvath KJ and Simon Rosser BR. Associations between partner-venue specific personal responsibility beliefs and transmission risk behavior by HIV-positive men who have sex with men (MSM). AIDS Behav. 2013; 17:1855-61. | Article | PubMed Abstract | PubMed Full Text

20. Rosser BR, Gurak L, Horvath KJ, Oakes JM, Konstan J and Danilenko GP. The Challenges of Ensuring Participant Consent in Internet-based Sex Studies: A Case Study of the Men's INTernet Sex (MINTS-I and II) Studies. J Comput Mediat Commun. 2009; 14. | Article | PubMed Abstract | PubMed Full Text

21. Martinez-Perez B, de la Torre-Diez I and Lopez-Coronado M. Mobile health applications for the most prevalent conditions by the World Health Organization: review and analysis. J Med Internet Res. 2013; 15:e120. | Article | PubMed Abstract | PubMed Full Text

22. Fry JP and Neff RA. Periodic prompts and reminders in health promotion and health behavior interventions: systematic review. J Med Internet Res. 2009; 11:e16. | Article | PubMed Abstract | PubMed Full Text

23. Gerend MA and Magloire ZF. Awareness, knowledge, and beliefs about human papillomavirus in a racially diverse sample of young adults. $J$ Adolesc Health. 2008; 42:237-42. | Article | PubMed

24. Narouz N, Allan PS and Wade AH. Genital herpes: general practitioners' knowledge and opinions. Sex Transm Infect. 2002; 78:198-200. | Article | PubMed Abstract | PubMed Full Text

25. Bednarczyk RA, Birkhead GS, Morse DL, Doleyres H and McNutt LA. Human papillomavirus vaccine uptake and barriers: association with perceived risk, actual risk and race/ethnicity among female students at a New York State university, 2010. Vaccine. 2011; 29:3138-43. | Article I PubMed

26. Sundstrom K, Tran TN, Lundholm C, Young C, Sparen P and Dahlstrom LA. Acceptability of HPV vaccination among young adults aged $18-30$ years-a population based survey in Sweden. Vaccine. 2010; 28:7492-500. | Article I PubMed

27. Graham AL, Papandonatos GD, Bock BC, Cobb NK, Baskin-Sommers $A$, Niaura R and Abrams DB. Internet- vs. telephone-administered questionnaires in a randomized trial of smoking cessation. Nicotine Tob Res. 2006; 8 Suppl 1:S49-57. | Article | PubMed Abstract | PubMed Full Text

28. Graham AL and Abrams DB. Reducing the cancer burden of lifestyle factors: opportunities and challenges of the Internet. J Med Internet Res. 2005; 7:e26. | Article | PubMed Abstract | PubMed Full Text

29. Graham AL and Papandonatos GD. Reliability of internet- versus telephone-administered questionnaires in a diverse sample of smokers. J Med Internet Res. 2008; 10:e8. | Article | PubMed Abstract | PubMed Full Text

30. Fox S. Pew Internet: Health. Pew Internet \& American Life Project, Editor. 2013. | Website

\begin{tabular}{l} 
Citation: \\
Hill MJ and Grimes RM. A pilot study assessing \\
whether African American women visiting the \\
emergency department give different answers \\
than an anonymous, internet-based population. \\
Emerg Med Health Care. 2014; $2: 2$. \\
http://dx.doi.org/10.7243/2052-6229-2-2 \\
\hline
\end{tabular}

